\title{
Effect of Variability of Fly Ash Obtained from the Same Source on the Characteristics of Geopolymer
}

\author{
Antoni $^{1,{ }^{*}}$, Juan Satria ${ }^{1}$, Agung Sugiarto ${ }^{1}$, and Djwantoro Hardjito ${ }^{1}$ \\ ${ }^{1}$ Department of Civil Engineering, Petra Christian University, Indonesia
}

\begin{abstract}
Geopolymer properties is notably influenced by the quality of fly ash used as the precursor material. Fly ash obtained from the same source may have varying physical and chemical characteristics. The characteristics are influenced by, among other, the method and temperature of burning, the degree of grinding and the quarry sources of the coal. In this study, high calcium fly ash from a single power plant was investigated, to analyze the effect of its variability on the characteristics of geopolymer mortar. Fly ash samples were collected at ten different sampling periods. Three mixture compositions, with different sodium silicate solution to sodium hydroxide ratios, were prepared to produce geopolymer mortars. From the results, it was found that there are broad variation of fly ash chemical properties, however only small variation on the fineness and LOI was discovered. The setting time and compressive strength of geopolymer are influenced by the fly ash particle size, $\mathrm{pH}$ value and chemical content. Higher level of calcium oxide content increases the compressive strength, while finer particle size could have effect on the later age increase of the compressive strength. Faster setting time is also correlated with the higher $\mathrm{pH}$ value of the fly ash, with the tendency of flash setting occurrence for geopolymer using fly ash of high $\mathrm{pH}$ level.
\end{abstract}

\section{Introduction}

Fly ash based geopolymer concrete has been researched extensively due to the availability of fly ash in many regions. Fly ash, as a waste product from boiler burning process in factory and power plant, consequently has very broad quality range, depending on the variability of the coal quality and the burning process. Fly ash quality and its suitability to be used as precursor material in making geopolymer is determined by the source of the fly ash, its chemical composition, and physical shape and size of the fly ash. The presence of unburned coal, shown by the loss on ignition (LOI), is also a significant factor in classifying fly ash quality, as fly ash with higher LOI would absorb the alkaline activator in a higher rate, and reduce the geopolymer reaction $[1,2]$.

\footnotetext{
*Corresponding author: antoni@petra.ac.id
} 
In ordinary concrete technology, fly ash is classified into the low calcium and high calcium fly ash, to differentiate the hydration reaction and pozzolanic reaction with the calcium hydroxide. Thus, this classification is also applicable in the fly ash-based geopolymer concrete technology. Low calcium fly ash causes more predictable setting time of geopolymer, due to its low calcium content [3-5]. Low calcium fly ash geopolymer commonly has long setting time and requires heat for curing. On the other hand, high calcium fly ash creates challenges, when it is used for making geopolymer concrete [6-8]. Higher strength is typically obtainable when using high calcium fly ash, however the occurrence of rapid setting may hinder its application in large volume.

The authors' previous studies $[9,10]$ have found that fly ash obtained from different power plants in Java island, Indonesia, produced different properties of the resulting geopolymer mortar. Setting time and compressive strength are affected by the physical and chemical properties of the fly ash used. The physical properties of fly ash are revealed by its particle size distribution, particle shape and the presence of contaminant in the fly ash, while the chemical properties are shown by the chemical compositions and LOI. The type of alkaline activator used in making the geopolymer significantly affects the properties of geopolymer. Fly ash obtained from one source stood out by having the strength of resulting geopolymer of almost double than those obtained from other sources, while maintaining the same mixture composition.

As the coal used in a power plant may be obtained from several quarries and the power plant may only interested in obtaining the highest energy, the quality of the fly ash produced could differs significantly between shipments. The difference also includes the calcium content in the fly ash.

In the current study, the suitability of fly ash obtained from one high quality source as precursor for making geopolymer mortar is investigated. Variations of fly ash quality, collected from different sampling time, are studied. The resulting fresh and hardened properties of the geopolymer mortar are correlated with physical and chemical properties of fly ash.

\section{Experimental methods}

Materials. Fly ash samples for making geopolymer were obtained from a power plant located in Paiton, East Java, Indonesia. It was reported as a good precursor for making good geopolymer [10]. A combination of chemical grade sodium hydroxide $(\mathrm{NaOH})$ and sodium silicate solution was used as the alkaline activator. Sodium silicate solution was composed of $16.27 \% \mathrm{Na} 2 \mathrm{O}, 38.23 \% \mathrm{SiO} 2$ and $45.5 \% \mathrm{H} 2 \mathrm{O}$. Sand was obtained from Lumajang quarry and conditioned to conform to standard sand gradation of ASTM C778 [11].

Mixture and Testing. The following mixture composition was used to produce geopolymer mortar, i.e. sand to fly ash mass ratio of 2 , distilled water to fly ash ratio of $0.25,8 \mathrm{M} \mathrm{NaOH}$ concentration, and sodium silicate liquid to sodium hydroxide solid ratio $(\mathrm{S} / \mathrm{N})$ were at 2, 2.5 and 3, respectively. Mixing was carried out using hand drill and performed in small batches to produce three $50 \mathrm{~mm}$ cubes, as it was found that there was tendency of rapid setting. Vicat setting time measurement was conducted on geopolymer paste at room condition [12]. Paste mixture was the same mixture proportion as the mortar, only without sand. The mortar mixture was cast in the $50 \mathrm{~mm}$ cube mould for compressive strength testing at 7,14 and 28 days. After casting, the mould was covered with plastic sheet, and placed in the oven at $60^{\circ} \mathrm{C}$ for 24 hours. After demolding, the specimens were cured in laboratory room condition until the day for compressive testing. Each data represents the average result from three compressive strength tests. 


\section{Results and discussion}

Fly Ash Variability. Ten samples of fly ash were collected within the period of four months, from July to October 2015, with one to two weeks intervals. Fly ash from Paiton power plant in East Java is considered as good quality fly ash with very low LOI. Table 1 shows the $\mathrm{pH}$ and fineness of ten samples of fly ash, as the proposed rapid indicators for the quality of the fly ash. Values of $\mathrm{pH}$ were measured from solution of 80 gram distilled water and 20 gram fly ash. Table 2 shows the chemical composition of selected fly ash samples as measured from XRF test. LOI values were consistently less than $1 \%$. Fly ash samples have medium to high content of $\mathrm{CaO}$, ranges from $9.40 \%$ to $20.42 \%$. It was found that the $\mathrm{pH}$ values correlate with the content of calcium oxide $(\mathrm{CaO})$ and magnesium oxide $(\mathrm{MgO})$ compounds. The physical properties was measured only by sieving the fly ash passing sieve \#325 (smaller than $44 \mu \mathrm{m}$ ). It was found that fly ash used in this study has a consistent fineness, with the exception of FA3, that has $76 \%$ particle size finer than $44 \mu \mathrm{m}$.

Setting Time. Setting times of geopolymer paste using four different fly ash samples as measured using Vicat needle are shown in Fig. 1. Higher alkali activator ratio $(\mathrm{S} / \mathrm{N})$ causes longer setting time as the higher content of sodium silicate solution increases the wetness of the mixture. It is shown that the high $\mathrm{pH}$ values of more than 11.0 correlate with the occurrence of fast setting. FA4 with $\mathrm{pH}=11.8$ produces the fastest setting time of geopolymer paste at about 10 minutes. Different behavior was shown on FA2 and FA10, with only $0.1 \mathrm{pH}$ value difference, whereby the setting times of geopolymer paste were very contrast. FA2 causes significantly longer setting time than FA10. Davidovits [13] classifies the $\mathrm{pH}$ range of fly ash of 8 to 11 that may cause rapid setting, while high possibility of flash setting may occur when $\mathrm{pH}$ value of fly ash is more than 11 . With the exception of FA2, this study confirms the classification. However, the setting behavior could be affected also by other factors besides $\mathrm{pH}$, especially for the ones with $\mathrm{pH}$ values about 11 .

The results also showed that for geopolymer paste without any flash setting tendency, the higher the $\mathrm{S} / \mathrm{N}$ ratio, the longer the setting time. But, for those with flash setting tendency, the $\mathrm{S} / \mathrm{N}$ ratio does not really affect the setting time.

Table 1. $\mathrm{pH}$ value and particle fineness of the fly ash samples

\begin{tabular}{|c|c|c|c|c|c|c|c|c|c|c|}
\hline & FA1 & FA2 & FA3 & FA4 & FA5 & FA6 & FA7 & FA8 & FA9 & FA10 \\
\hline $\mathrm{pH}$ & 10.9 & 11.1 & 10.4 & 11.8 & 10.6 & 10.8 & 10.6 & 11.7 & 11.4 & 11.2 \\
\hline Passing sieve \#325 $(44 \mu \mathrm{m})(\%$, mass $)$ & 84 & 88 & 76 & 88 & 80 & 84 & 84 & 88 & 92 & 84 \\
\hline
\end{tabular}


Table 2. XRF results for selected fly ash samples

\begin{tabular}{|c|c|c|c|c|c|}
\hline \multirow{2}{*}{ No. } & \multirow{2}{*}{ Compound } & \multicolumn{4}{|c|}{ Chemical Composition (\%, by mass) } \\
\cline { 3 - 6 } & & FA2 (11.1) & FA3 (10.4) & FA4 (11.8) & FA5 (10.6) \\
\hline 1 & $\mathrm{SiO}_{2}$ & 43.74 & 43.36 & 32.47 & 42.26 \\
\hline 2 & $\mathrm{Al}_{2} \mathrm{O}_{3}$ & 22.03 & 29.74 & 14.92 & 24.43 \\
\hline 3 & $\mathrm{Fe}_{2} \mathrm{O}_{3}$ & 14.68 & 7.33 & 16.50 & 12.91 \\
\hline 4 & $\mathrm{TiO}_{2}$ & 1.28 & 1.00 & 0.71 & 1.01 \\
\hline 5 & $\mathrm{CaO}$ & 9.40 & 13.30 & 20.42 & 11.19 \\
\hline 6 & $\mathrm{MgO}$ & 4.33 & 1.80 & 7.95 & 3.69 \\
\hline 7 & $\mathrm{Cr}_{2} \mathrm{O}_{3}$ & 0.14 & 0.00 & 0.14 & 0.01 \\
\hline 8 & $\mathrm{~K}_{2} \mathrm{O}$ & 1.55 & 0.42 & 1.32 & 0.80 \\
\hline 9 & $\mathrm{Na}_{2} \mathrm{O}$ & 1.56 & 1.88 & 2.92 & 1.85 \\
\hline 10 & $\mathrm{SO}_{3}$ & 0.53 & 0.40 & 1.88 & 0.91 \\
\hline 11 & $\mathrm{Mn}_{2} \mathrm{O}_{3}$ & 0.15 & 0.14 & 0.18 & 0.24 \\
\hline 12 & $\mathrm{LOI}_{2}$ & 0.80 & 0.60 & 0.43 & 0.44 \\
\hline $\mathrm{SiO}_{2}+\mathrm{Al}_{2} \mathrm{O}_{3}+\mathrm{Fe}_{2} \mathrm{O}_{3}$ & 80.45 & 80.43 & 63.89 & 79.60 \\
\hline \multicolumn{2}{|c|}{$\mathrm{SiO}_{2} / \mathrm{Al}_{2} \mathrm{O}_{3}$} & 1.99 & 1.46 & 2.18 & 1.73 \\
\hline
\end{tabular}

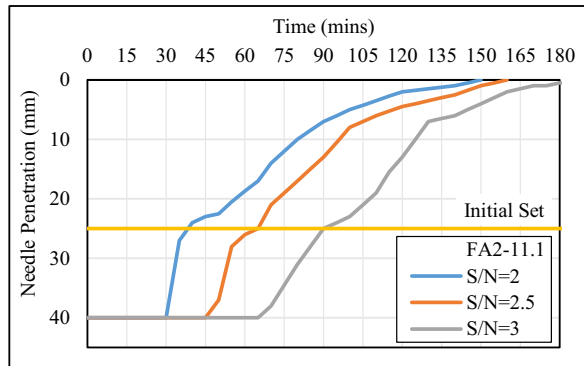

(a)

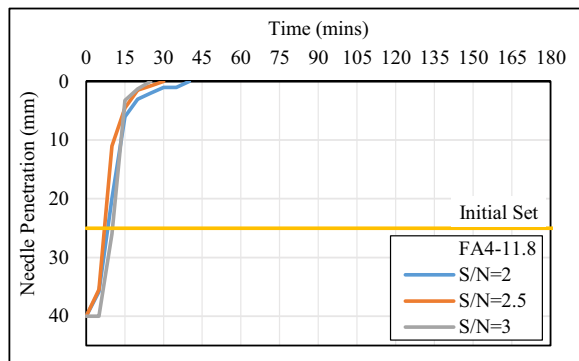

(c)

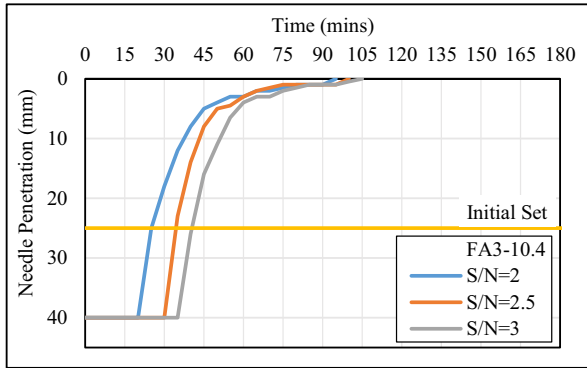

(b)

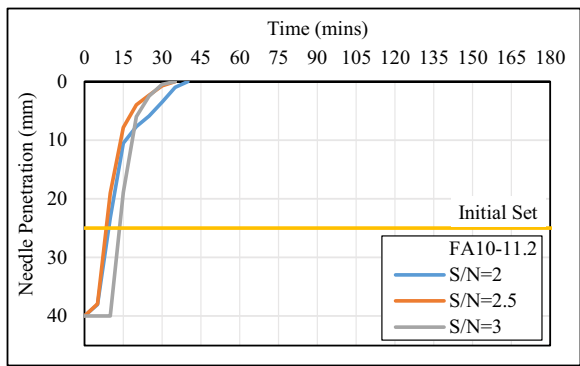

(d)

Fig. 1. Setting time of geopolymer paste using four different fly ash samples, (a) FA2-pH 11.1, (b) FA3-pH 10.4, (c) FA4-pH 11.8 and (d) FA10-pH 11.2

Compressive Strength. The effect of fly ash variability and $\mathrm{S} / \mathrm{N}$ ratio on the compressive strength of geopolymer mortar are shown in Fig. 2. The series was sorted based on the $\mathrm{pH}$ values of the fly ash, from the lowest to the highest. The results show that all geopolymer samples have initial strength at 7 days higher than $55 \mathrm{MPa}$. Most samples show the increase of compressive strength with age, although the rates vary with the variability of fly ash. It was found that there was a large increase of compressive strength between 14 and 28 days for those with FA2, FA4, FA8, and FA9; while there was only slight increase of strength for the other fly ashes. The highest compressive strength of 85.0 $\mathrm{MPa}$ was achieved by mortar with FA4, with $\mathrm{S} / \mathrm{N}$ ratio of 2.5 , at 28 days. The compressive strength of geopolymer mortar normally reaches a plateau at later age, after thermal curing, 
as indicated by Chindaprasirt et al. [7]. The increase at later age strength suggest that there could be a hydration reaction takes place beside the geopolymer reaction. The increase of compressive strength with age for high calcium fly ash geopolymer was also stated by Gou et al. [6] and Nurwidayati et al. [14], but no further discussion was made. The effect of different $\mathrm{S} / \mathrm{N}$ ratios on the compressive strength does not show any single trend.

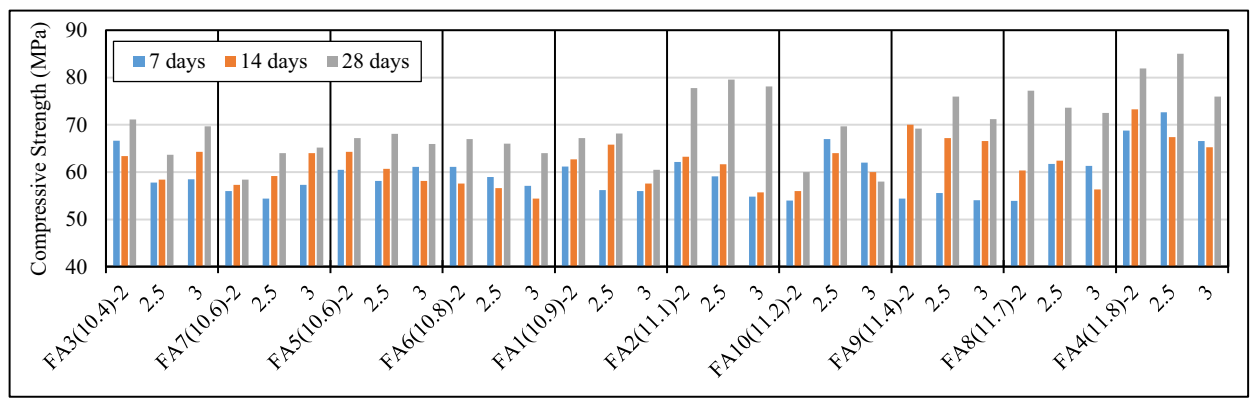

Fig. 2. Effect of variability of fly ash and $\mathrm{S} / \mathrm{N}$ ratio on compressive strength of geopolymer mortar

Strength Gain. The increase of the compressive strength from 7 to 28 days with the rapid indicators of the fly ash is shown in Fig. 3. Lower compressive strength values show the 7 days strength and linked with the higher values for the 28 days strength. From the figure, it is shown that the higher increase of compressive strength from 7 to 28 days occurs to the geopolymer mortar with higher $\mathrm{pH}$ value fly ashes. The trend is true with exception of FA10, showing only small increment. Fig 3(b) shows the effect of material fineness with the strength increment. There is a good correlation between finer materials with the increase of compressive strength. This condition shows that there could be an additional hydration reaction in the geopolymer mortar due to the high calcium content in the fly ash. The bigger strength gain is also attributed by the finer particle size of the fly ash.

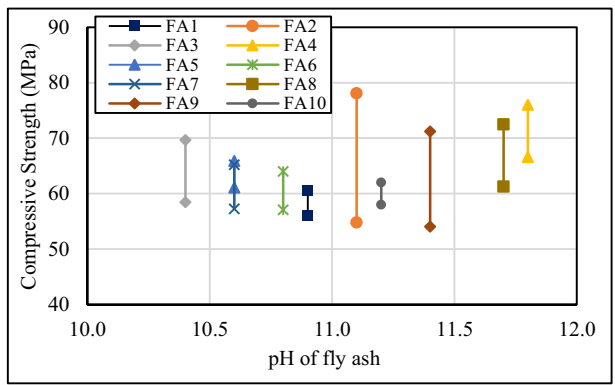

(a)

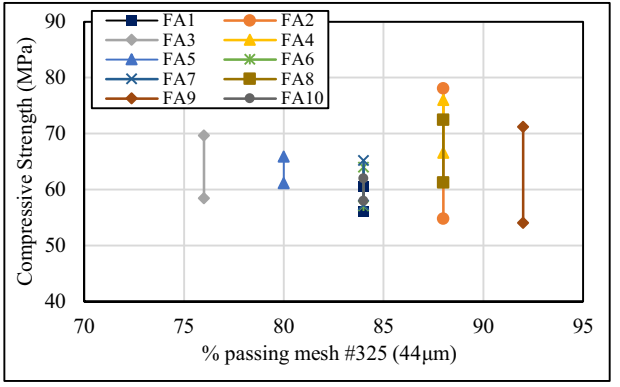

(b)

Fig. 3. Effect of fly ash properties on the increase of compressive strength from 7 to 28 days for geopolymer mixture with $\mathrm{S} / \mathrm{N}=3$, (a) $\mathrm{pH}$ effect and (b) particle fineness.

\section{Conclusions}

Fly ash obtained from one power plant with various sampling time was used to made geopolymer mortar. The following findings was obtained:

There is a large variation, in term of the chemical properties, of the fly ash collected from the same source in various sampling time. This may cause large variation in the compressive strength and setting time of the resulting geopolymer mortar. The high $\mathrm{CaO}$ content in the fly ash can increase the compressive strength due to additional hydration 
reaction that may take place. However, the higher content of $\mathrm{CaO}$ may increase the possibility of flash setting time occurrence.

On the physical properties, i.e. the particle size and LOI, it was found that the fly ash studied has good and relatively constant properties. This may be attributed as the source of excellent compressive strength of resulting geopolymer mortar, higher than $50 \mathrm{MPa}$, with the range of 58 to $85 \mathrm{MPa}$ for 28 days compressive strength.

Two rapid indicators, namely $\mathrm{pH}$ value and \% passing sieve \#325, can be good indicators to assess the quality of the fly ash, given the suitability of the fly ash as source material for making geopolymer has been confirmed.

The authors acknowledge the financial support from Ministry of Research, Technology and Higher Education, Indonesia, in this research study.

\section{References}

1. J. van Jaarsveld, J. van Deventer, G. Lukey, Mater. Lett. 57, 1272 (2003)

2. E. Diaz, E. Allouche, S. Eklund, Fuel 89, 992 (2010)

3. D. Hardjito, C. Chua, C. Ing, Modern applied science, 2, 3 (2008)

4. C. Montes, E. Allouche, Coal Combustion and Gasification Products, 4, 1 (2012)

5. S.E. Wallah, Civil Engineering Dimension 12, 73(2010)

6. X. Guo, H. Shi, W. Dick, Cement Concrete Comp., 32, 142 (2010)

7. P. Chindaprasirt, J. Mater. Civ. Eng., 23, 264 (2010)

8. S. Pangdaeng, Mater. Design., 53, 269 (2014)

9. Antoni, S. Wijaya, D. Hardjito, Mater. Sci. Forum., 841, 90 (2016)

10. Antoni, S. Wijaya, D. Hardjito, Mater. Sci. Forum., 841, 98 (2016)

11. ASTM C778. Standard Specification for Standard Sand. ASTM International, (2002)

12. ASTM C191, Standard Test Method for Time of Setting of Hydraulic Cement by Vicat Needle, ASTM International, (2004)

13. J. Davidovits, Geopolymer Chemistry and Applications, Institut Geopolymere, France, 390-394 (2008)

14. R. Nurwidayati, Mater. Sci. Forum., 841 (2016) 